The case concerned a man who had multiple rib fractures and associated surgical emphysema. To give such a patient positive pressure assisted ventilation without prior placement of a chest drain is to court disaster. It was perhaps fortunate that this man did not rapidly develop a tension pneumothorax with mediastinal shift. We would like to underline the importance of the presence of surgical emphysema in a patient with rib fractures. The presence of air in the tissues must be taken to signify perforation of the lung surface and should alert the clinician to the need for an intercostal drain to be inserted before, or in a dire emergency as soon as possible after, giving positive pressure ventilation.

HOWARD BORKETT-JONES

R F WEEKS

St Richard's Hospital,

West Sussex PO19 4SE

\section{Dysphagia in acute stroke}

SIR,-The article on dysphagia in acute stroke by Dr Caroline Gordon and colleagues (15 August, p 411) does not mention the findings on oesophageal manometry in such patients.

The cause of dysphagia associated with strokes may be oropharyngeal, owing to inability to initiate the act of swallowing, or pharyngo-oesophageal, owing to lack of coordination at the cricopharyngeal level. These are probably due to an upper motor neurone lesion of the lower cranial nerves (IX, X, and $\mathrm{XI}$ ), and, as Dr Gordon and coworkers suggest, lower cranial nerve lesions are more common in patients with dysphagia associated with stroke (brain stem strokes). The lack of coordination at the pharyngo-oesophageal level shown by manometry when the cricopharyngeal relaxation fails to occur at the same time as the pharyngeal contractions results in dysphagia and aspiration into the tracheobronchial tree. This manometric finding is similar to that seen in patients with cricopharyngeal diverticulae. In association with a stroke, however, the coordination is, as shown by Dr Gordon and colleagues, self limiting to a few days, and full recovery usually follows. Therefore, while chest infections are common, a cricopharyngeal diverticulum does not develop.

The patients need to have their nutrition maintained during the period of dysphagia as well as having their lungs protected from aspiration and pneumonitis. In the occasional case where the coordination is not restored a cricopharyngeal sphincterotomy ensures normal swallowing and is a fairly minor procedure.

D PRAKASH

Hairmyres Hospital,
Glasgow G75 8RG

1 Castell DO, Johnson LF. Oesophageal function in health and disease. Amsterdam: Elsevier, 1983.

2 Fischer RA, Ellison GW, Thayer WR, Spiro HM, Glasser GM Esophageal motility in neuromuscular disorders. Ann Intern Esophageal motility in $1965 ; 63: 229-48$.
Med

3 Kilman WJ, Goyet RL. Disorders of pharyngeal and upper esophageal sphincter motor junction. Arch Intern Med 1976; 136:592-601.

\section{Mobilising anger against tobacco}

SIR,-Several years ago, in the USA, some mothers whose teenage children had been killed in road accidents became angry because little was done by those in authority to combat the problem. So they got together and formed MADDMothers Against Drunken Driving. In those states where they have been active they have been effective. We need a similar angry group in Britain of relatives, friends, and carers against cigarettes and tobacco.

The tactics of the tobacco industry never fail to outrage me. Your news item of 12 September ( $p$ 679) showed the continuing problem of sport sponsorship by tobacco companies, who need to recruit at least 200 new smokers daily to replace the number dying prematurely from smoking related diseases each day in the United Kingdom.

Dr Colin Campbell, describing the death of a young woman from lung cancer said, "I cannot tell you how angry I am that cigarettes stubbed out this woman's life. Perhaps the time has come to subvert this pious nonsense about freedom of choice and the right to smoke in a free country" ( 25 July, p 265). Dr Campbell is right, of course. Perhaps we haven't been angry enough. By using a lot of our energy trying to get a better voluntary agreement on tobacco advertising, we have lost sight of the real problem.

We need to channel our anger and do as the mothers of MADD have done. I cannot think of an acronym. If anyone has any suggestions please write and tell me.

South Birmingham Health Authority,

David A Player

Selly Oak, Birmingham B29 6JF

\section{Surgery of morbid obesity}

SIR,-With regard to the reply by Mr J C Gazet and Professor T R E Pilkington to our letter (5 September, p 605) we believe that further clarification is necessary. We agree that patience is necessary before conclusions are drawn after gastric restrictive procedures, but it should also be emphasised that successful results are going to be achieved only if this surgery is performed by surgeons with a special interest and patients. are selected very carefully. It is not correct that only Scopinaro has substantial experience of biliopancreatic bypass; there are now several reports of other centres' experience with this procedure. ${ }^{1-4}$

Gastric restrictive procedures produce impressive short term weight loss in selected patients. Pouches are now much smaller than $50 \mathrm{ml}$ (often $10-20 \mathrm{ml}$ ), and these do not impair normal eating for life. Restriction persists for only one to two years and at most for about five years, unless the patient develops some complication, such as outlet stomal stenosis.

We did not state that gastric bypass is easy to reverse but that vertical banded gastroplasty is. This was done on one occasion without morbidity, and it was technically easy to perform a gastrogastrostomy between the proximal pouch and distal stomach. We have also revised four of our earlier $5.5 \mathrm{~cm}$ vertical banded gastroplasties by a technique previously described. ${ }^{4}$ This proved straightforward on all occasions, the only morbidity being wound sepsis in one case.

Finally, with the advent of more sophisticated stapling instruments, such as the four row stapler, bariatric procedures have become simpler and safer, and the consequent reduction in morbidity and mortality has made them more acceptable.

\section{E R T C OWEN} A E KARK

Northwick Park Hospital Middlesex HA1 3UJ

1 Wittig JH. Biliopancreatic bypass: preferred revision for failed gastric restrictive and jejunoileal bypass procedures. Int $f \mathrm{Obes}$ 1987;11(suppl 2): 121 .

Holian DK, Clare MW. Reversal rare following biliopancreatic bypass. Int f Obes 1987;11(suppl 2):121.

Clare MW, Holian DK. Effects of biliopencreatic bypass on body composition analysis. Int $\mathcal{J}$ Obes 1987;11(suppl 2): 124 .

4 Owen ERTC, Kark AE. Proximal gastric pouchplasty for revision of failed vertical banded gastroplasty. Int $\mathcal{I}$ Obes 1987;11(suppl 2):115.
Cardiovascular effects of training for a marathon run

SIR,-With reference to the paper by Dr Iain N Findlay and colleagues (29 August, p 521), I would like to point out that lowering total serum cholesterol and low density lipoprotein cholesterol concentrations may be achieved by less dramatic means than those used in their study.

We conducted a study in which 16 subjects ran an average of 5.8 miles weekly (range 3.7 to 10 miles) ${ }^{1}$ in contrast to the average of 22.1 miles weekly (range 12 to 35 miles) of the subjects in the study by Dr Findlay and coworkers. We found falls of $5.7 \%$ in total serum cholesterol concentration $(p<0.02)$ and $8.3 \%$ in low density lipoprotein cholesterol concentration $(p<0.02)$. These effects were most pronounced in those running over 6 miles weekly. Like Dr Findlay and colleagues, we found no significant change in serum high density lipoprotein cholesterol or triglyceride concentration, although other studies in which joggers have run over 11 miles weekly have shown increases in high density lipoprotein cholesterol concen-

Though we did not detect as great a reduction in total serum cholesterol concentration as the $12 \%$ found by Dr Findlay and colleagues, it seems that useful improvement in blood lipid concentrations may be achieved by jogging without the need to undertake marathon training. Jogging for 6 miles or more weekly seems adequate in this respect.

Central Middlesex Hospital

B KAUFMAN

London NW10 7NS

Kaufman S, Kaufman B, Reynolds D, Trayner I, Thompson GR. Effect of jogging on serum low density lipoprotein GR. Effect of jogging on serum

2 Harley Hartnung G, Foreyt JP, Mitchell RE, Vlasek I, Gotto AM. Relation of diet to high density lipoprotein cholesterol in middle aged marathon runners, joggers and inactive men. N Engl f Med 1980;302:357-61.

SIR,-Since the observation in 1953 that bus drivers and postal clerks were more prone to heart disease than conductors and postmen, ${ }^{1}$ there has been a continuing interest in the protective effects against heart disease of physical activity.

The results reported by $\mathrm{Dr}$ Iain $\mathrm{N}$ Findlay and colleagues (29 August, p 521) agree in general with those of other studies and show time related reductions in plasma lipid concentrations and blood pressure. Dr Findlay and coworkers concluded that there was an independent effect of exercise on blood pressure and noted that their results implied a "continuing reduction in peripheral vascular resistance." A comparable study by Australian workers showed that total peripheral resistance and mean arterial pressure decreased in parallel with increased frequency of exercise. ${ }^{2}$ Furthermore they concluded that the change in arterial blood pressure was due entirely to the reduction in total peripheral resistance. They speculated that changes in size or an increase in the number of skeletal muscle capillaries might explain the reduction in peripheral resistance, although they were not sure that the time involved was long enough for such changes to occur.

It is not necessary, however, for vascular changes to occur to increase peripheral resistance. Increased blood viscosity with reduced red cell deformability also increases peripheral reistance, and hypertension associated with increased blood viscosity has been reported by several groups. ${ }^{3-5}$ When diet is changed to eliminate animal products or to increase fish intake or when fish oil is taken as a dietary supplement blood pressure is reduced. Such dietary changes also reduce blood viscosity. It seems that the beneficial effects of exercise are 